\title{
Game-based learning in an Industrial Service Operations Management Course
}

\author{
Tetik, Müge ${ }^{\text {a }}$ Öhman, Mikael ${ }^{\text {; }}$; Rajala, Risto ${ }^{\text {b }}$ and Holmström, Jan ${ }^{\text {b }}$ \\ ${ }^{\mathrm{a}}$ Department of Civil Engineering, Aalto University, Finland, ${ }^{\mathrm{b}}$ Department of Industrial \\ Engineering and Management, Aalto University, Finland
}

\begin{abstract}
This study explores how a game-based approach supports students' learning in a graduate course on industrial service operations management. Aalto Manufacturing Game (AMG) has been played for several years as a part of an Industrial Management course to provide students with a realistic view of industrial services and asset management. The game illustrates supply chain dynamics and asset management challenges, with a focus on the quality deterioration problem in service provision (Oliva \& Sterman, 2001). In this paper, we evaluate the effect of AMG on participants' learning based on game session feedback and written exam answers. We also evaluate the game as a learning experience through feedback, observations, and interviews. The findings suggest that the gamified version of teaching provides students with the opportunity to learn by doing while having fun in the class. The game enables participants to socially construct knowledge, raising the effectiveness of teaching supply chain challenges by simulating real world problems from different perspectives of actors involved in operations. Based on our research we argue that the game enhances the learning experience through emotionally engaging students in the activity. To this end, the learning objectives should be embedded in the game dramaturgy.
\end{abstract}

Keywords: Teaching game; Service operations; Gamification. 


\section{Introduction}

The nature of operations management is changing in many industries, as the role of services is increasingly important in the offerings of capital goods manufacturers (Oliva \& Kallenberg, 2003). In contrast to producing goods, producing services present unique challenges from an operations management perspective, as they are essentially co-produced by supplier and customer. As a consequence, manufacturers accustomed to managing closed production systems, are faced with ever more open systems where increased interdependence among actors translate to increased complexity and uncertainty in production. This is reflected back on operations management teaching, which needs to prepare students for the complex dynamic environment they will be facing.

Game-based learning has been used to support the learning of complex dynamic phenomena with significant feedback-mechanisms in fields such as military, aeronautics, medicine, management, and engineering (Pasin \& Giroux, 2011). The Aalto Manufacturing Game (AMG) teaches the service quality deterioration problem (Oliva \& Sterman, 2001) in industrial services, which is a challenging subject to teach due to its inherent complexity characterized by uncertainty and trust issues between service supplier and customer. Despite being a simplification of reality, AMG captures key contextual complexities and offers an immersive experience to participants, who get to experience industrial service operations management challenges first hand from the perspective of the role they are playing.

With AMG being an optional part of the Service Operations Management (SOM) course, we are able to evaluate differences in learning between those who participated in the game, and those who did not. We find that the students who participated in the game could, in a written exam, better articulate the contextual challenges and solutions experienced in the game. Further, through observations of game sessions and participant interviews and feedback, we can also discuss the game session as a learning experience, related to which we highlight the role of emotional engagement in the game situation as a driver of learning. Based on our observations, we discuss how the current game could be developed, along with more general observations for developing game-based teaching.

\section{Literature Review}

Simulations, including games, have been used and recognized as an effective teaching method (Faria, 2001), enabling students to test their existing knowledge and skills and obtain new ones. Games can illustrate advantages and disadvantages of a situation and facilitate forming different strategies (Kriz, 2003). Modeling diverse situations, participants' behavior and solutions can be observed. Also, games provide opportunities to 
make mistakes while not having to concern about adverse outcomes (Geithner \& Menzel, 2016). Thus, participants make changes in simulated games without the fear of damaging a real-life system.

In games, participants interact with others and the game. According to Mayer et al. (2011), the transfer of learning is positively affected when the participants work together in a simulation setting. The interactive nature of games encourages active student participation, based on which game-based teaching has been argued to be a more suitable method for today's students, compared to, e.g. traditional lectures (Proserpio \& Gioia, 2007). According to Ammar and Wright (1999) simulations are of great use in operations management teaching, where an understanding of challenging and complex operations management concepts benefits from the first-hand experience. Further, Lewis and Maylor (2007) note that almost half of the organizational games have OM-specific themes, implying that the field of OM has adopted games as a useful teaching method.

The learning types that can be associated with the games are active, collaborative and constructivistic learning. Active learning is a method in which students grasp the insights by discovering. It comprises a set of instructional procedures for heavily involving the participants (Wilson \& Sipe, 2014). Via collaborative learning, learners pursue a task together. It suggests that the knowledge is built in a group in which the participants connect each other through sharing their experiences and take on different roles (Mitnik, Recabarren, Nussbaum, \& Soto, 2009). Constructivistic learning is learning of the individuals through interacting each other and their environment, where the teacher takes the role of a facilitator rather than a lecturer. Kim (2005) suggests that the interaction among the participants is important as the instructor can design the best solution and help in discovering a solution and supervise participants' progress. Thus, collaborative learning tools such as games are required to achieve this type of learning.

\section{Aalto Manufacturing Game}

The AMG has been played for the last eight years at Aalto University by graduate students in industrial engineering and management, taking the service operations management course. The course comprises of lectures and article reviews, to which AMG is an optional complementary learning activity. Whereas the reading materials and lectures give a theoretical perspective on the subject, illustrative case examples and visiting lecturers from industry are also included to give some insight to practice. AMG is included to offer the students a chance of experiencing the theoretical and practical challenges first hand.

The game development process was iterative and included several test sessions to improve game design and playability. During The first phase of the process, the learning goals were 
built into the structure of the game. In the second phase, the game was tested by faculty with the objective of improving game characteristics and playability. In the third phase, the game was tested with two student groups, with a focus on improving the game design with respect to how well the game was able to reach its designated learning goals. Finally, after the game being included in the curriculum, experiences from game-sessions (3-4 per year) have been used to develop the game process, with a focus on the learning experience.

The learning objectives of AMG are to provide the participants with an experience on 1) diverging incentives within supply chains, 2) uncertainty caused by limited demand visibility and 3) balancing performing and improving. Coordination and communication between the members of the supply chain in the game are vital for each member achieving their performance goals. The interactions provide an environment to observe the motives of other members in order to grasp the significance of asset management in supply chain.

The basic setup of the game includes five teams; a distributor, two factories and two maintenance providers. Within the factory there is a designated Production Manager, as well as Machine Operators and Warehouse men. Factories produce boats, which are assembled from LEGO ${ }^{\circledR}$ bricks during gameplay. Each factory has two machines, which work in two shifts, enabling a maximum production of four boats per factory per turn. The boats produced by the factories are then sold to the distributor based on a negotiated price, while the distributor sells the boats onward to her final customers for a fixed price.

At the outset of the game, AMG is presented as a competitive game where each team should seek to maximize its profit and minimize its costs. The game standings are checked every 5 rounds, informing the teams of their standing relative to other teams. As the game progresses, the players experience the problems caused by conflicting incentives in the game setting. After the first part of the game, the participants are asked to reflect on solutions for the problems caused by conflicting incentives, upon which rules are changed so that game dynamics favor cooperation within the supply chains. Later, the rules are again changed to illustrate the introduction of condition monitoring technology to support maintenance decision-making. This change gives participants a firsthand experience in how decisions subject to risk become easier to make with increased visibility.

\section{AMG as a learning experience}

At the end of every game session participants are asked to fill out a feedback form, asking the participants to reflect upon what they have learned, how the game was as a learning experience and whether they had any ideas for improving the game. Further, for the last two years, the feedback form has also included Likert-scale evaluations which are intended to specifically gauge the game session as a learning experience. The results of the participants ( $\mathrm{N}=67$, from 6 different game-sessions) Likert evaluations are included in Table 1, debajo 
de, based on which we can make some interesting observations (role-specific averages are according to $\mathrm{D}=$ distributor $\mathrm{F}=$ factory and $\mathrm{M}=$ maintenance provider).

Table 1. Feedback

\begin{tabular}{|c|c|c|c|c|c|}
\hline \multirow{2}{*}{$\begin{array}{l}\text { Question } \\
\text { On a scale of 1 to 5, where } 1 \text { is "Disagree } \\
\text { completely" and } 5 \text { is "Totally agree" }\end{array}$} & \multicolumn{2}{|c|}{ All answers $(\mathrm{N}=67)$} & \multicolumn{3}{|c|}{ Role averages $(\mathrm{N})$} \\
\hline & Average & Variance & D (6) & F (44) & M (17) \\
\hline $\begin{array}{l}\text { The game was approachable and the rules were } \\
\text { easy to understand }\end{array}$ & 4,37 & 0,443 & 4,17 & 4,34 & 4,53 \\
\hline $\begin{array}{l}\text { I actively participated in my team's decision- } \\
\text { making }\end{array}$ & 4,45 & 0,884 & 4,20 & 4,61 & 4,12 \\
\hline $\begin{array}{l}\text { I was emotionally engaged in the game (I felt } \\
\text { angry/happy during the game) }\end{array}$ & 3,80 & 0,946 & 3,67 & 3,93 & 3,50 \\
\hline Winning the game was important for me & 3,50 & 1,098 & 3,33 & 3,60 & 3,29 \\
\hline Playing the game was a pleasant experience & 4,51 & 0,489 & 4,50 & 4,55 & 4,41 \\
\hline I mainly learned from observing the other teams & 2,76 & 1,197 & 3,33 & 2,43 & 3,41 \\
\hline $\begin{array}{l}\text { I mainly learned from discussing/deciding with } \\
\text { my team-mates }\end{array}$ & 3,71 & 1,266 & 2,40 & 4,20 & 2,82 \\
\hline Game-based learning works well for me & 4,42 & 0,542 & 3,67 & 4,43 & 4,65 \\
\hline
\end{tabular}

Overall the game-sessions were perceived as a pleasant experience, with little role-specific variation. Participants on average indicated that winning was important to them, which in turn correlated $(0,486)$ with the participants indicating that they felt emotionally engaged during the game-session. There was slight role-specific variation in emotional engagement and desire to win, with the factory-role being more engaging than the two other roles. Further, while participants in general felt that game-based learning worked well for them, there were significant role-specific differences, where maintenance providers gave the highest scores on this point. Whether game-based learning works well for the participant correlated with the extent to which the participants felt the game was approachable and the rules were easy to understand $(0,382)$ and to whether playing the game was a pleasant experience $(0,400)$.

In the course of the game sessions, we typically observed initial excitement when the participants explored their role and figured out what strategy they should use to win the game. As the initial excitement wore of, the emotions expressed in the session could be characterized as gradually growing frustration, as the behavior of the maintenance provider would mitigate any strategy pursued by factories or distributor. Before the end of the first part of the session, the frustration is quite tangible, with factory participants questioning the motives of the maintenance providers, through observed exclamations such as "How can we trust you?", "What does that mean, I don't understand!", "Are we sure that the cranes were maintained, shouldn't they be perfect?" and "Are you cheating on us?". 
There are role-specific differences in whether the participants participated actively in their team's decision-making, and whether they learned mainly from observing other teams, or discussing /deciding within their team. These differences stem from differences in team sizes, as distributors were the sole member of their team, and maintenance providers occasionally did not have other members in their team. Despite these roles also producing good results in terms of learning, the written feedback by some factory participants raised concerns that other roles did perhaps not learn as much from the game as the factories. Occasionally this was echoed by feedback from distributor and maintenance provider participants expressing a desire to also try out other roles during the game session. The role specific perspective was however also seen as the strength of the teaching approach as especially the maintenance provider experienced the conflicting incentives first-hand.

\section{Learning outcomes of AMG}

The students were asked to reflect on their learning in the session feedback forms, based on two open ended questions - "What were your key-learnings from playing AMG?" and "Did the game session give you any surprising insights on industrial service operations (things that you did not think of before playing the game)?". The answers to these questions reflect the learning objectives of the game, with slight differences in emphasis between students, which could reflect different student backgrounds. Roughly the half of the participants reported having surprising insights, and of those who did not, many still added that the game session did however provide an opportunity to see the (a priori known) theories in practice.

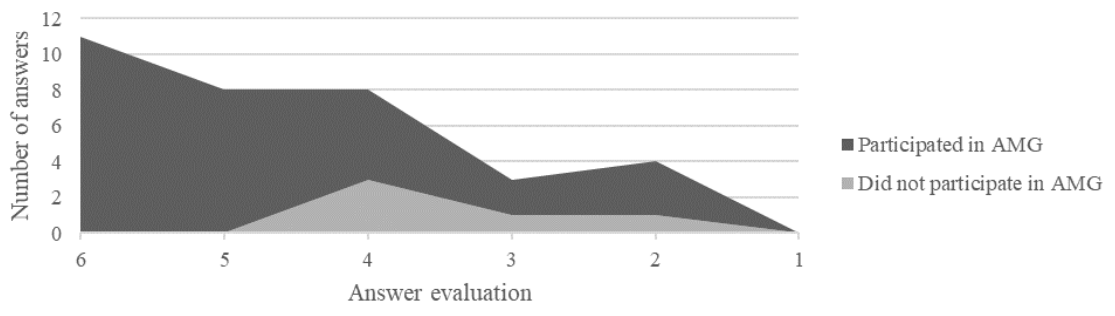

Figure 1. Exam (2016) answer evaluations (on a scale of 0-6)

The exam questions related to the learning objectives of the game were evaluated based on students' ability to elaborate on the mechanisms which were present in the game (excerpt of 2016 grading included in Figure 1). Due to the game being optional in the course, we were able to compare the exam answers of those who did, and those who did not participate in the game. When comparing good answers by students who participated in the game, with good answers by students who did not participate in the game, we observed a general tendency for game participants to write more articulate answers when reflecting theory 
against practice. We also noted that game participants were generally able to produce more in-depth elaboration on conflicting incentives, compared to those who did not participate in the game. There were however exceptions to both cases.

\section{Discussion}

In this paper we have studied game-based learning in a service operations management course. Based on our results we conclude that the AMG is an effective way to teach the service quality deterioration problem and the impact of misaligned incentives in industrial services. The AMG augments students' cognition about managing industrial services by embodying a built-in conflict between different stakeholders. The behaviors and intentional confrontations of the teams enable students to get acquainted with the multi-faceted context that involves the potential conflicts among actors. Our data shows that participants were emotionally engaged in the game, and, winning was important to them, which has been associated with positive effects on learning (Burguillo, 2010).

Educational games have been argued to foster a more comprehensive understanding of methods and concepts in complex systems (Kriz, 2003), enabling the modelling of different situations and different solutions for different roles. Based on the participant feedback the game helps students to understand the role of asset management as part of the supply chain, and especially the role-specific perspective to supply chain incentives. This was also reflected in the game participants' ability to elaborate on the exam questions using the learnings from AMG. The game enables participants to socially construct knowledge through facilitating collaborative and active learning as the participants are involved in the simulation and interact in order to achieve the goal shared by their team.

In developing the game sessions, we have sought to increase emotional engagement of the game participants, expecting it to lead to better learning experiences (Moon, 2004). The built-in conflict in the game works well in this respect, as it heightens tensions between the teams. However, the actions of the teacher as the facilitator of the game sessions is vital, as it can increase the tension by offering plausible, yet unlikely explanations for the experiences. Also, it can offer rational and theory-informed explanations of why things are going the way they go. Tensions are then defused in a constructive manor through changing game rules, so that the problems causing frustration no longer do so.

The focus on participant emotional engagement and the game as a learning experience has led us to see the experiential learning cycle manifested in game design, where participants within each game-round shift between abstract conceptualization, active experimentation, concrete experience and reflective observation in a continuous spiral (Kolb \& Kolb, 2005). Over the course of the game session, the learning objectives can be seen as having distinct 
dramaturgical curves, reaching their peaks where tension is defused through changing game rules. We argue that considering the above in game design (in terms of both structure and facilitation) enable teachers in the field of operations management to craft game-based learning experiences, preparing students for the ever increasing intricacy and complexity which characterizes the new normal in operations management.

\section{References}

Ammar, S., \& Wright, R. (1999). Experiential learning activities in Operations Management. International Transactions in Operational Research, 6(2), 183-197.

Burguillo, J. C. (2010). Using game theory and Competition-based Learning to stimulate student motivation and performance. Computers and Education, 55(2), 566-575.

Faria, A. J. (2001). The Changing Nature of Business Simulation/ Gaming Research: A Brief History. Simulation \& Gaming, 32(1), 97-110.

Geithner, S., \& Menzel, D. (2016). Effectiveness of Learning Through Experience and Reflection in a Project Management Simulation. Simulation and Gaming, 47(2), 228256.

Kim, J. S. (2005). Effects of a Constructivist Teaching Approach on Student Academic Achievement, Self-concept, and Learning Strategies. Asia Pacific Education Review, 6(1), 7-19.

Kolb, A. Y., \& Kolb, D. A. (2005). Learning styles and learning spaces: Enhancing experiential learning in higher education. Academy of Management Learning and Education, 4(2), 193-212.

Kriz, W. C. (2003). Creating effective learning environments and learning organizations through gaming simulation design. Simulation and Gaming, 34(4), 495-511.

Lewis, M. A., \& Maylor, H. R. (2007). Game playing and operations management education. International Journal of Production Economics, 105(1), 134-149.

Mayer, B. W., Dale, K. M., Fraccastoro, K. A., \& Moss, G. (2011). Improving Transfer of Learning: Relationship to Methods of Using Business Simulation. Simulation and Gaming, 42(1), 64-84.

Mitnik, R., Recabarren, M., Nussbaum, M., \& Soto, A. (2009). Collaborative robotic instruction: A graph teaching experience. Computers and Education, 53(2), 330-342.

Moon, J. A. (2004). A Handbook of Reflective and Experiential Learning. New York: RoutledgeFalmer.

Oliva, R., \& Kallenberg, R. (2003). Managing the transition from products to services. International Journal of Service Industry Management, 14(2), 160-172. 
Oliva, R., \& Sterman, J. D. (2001). Cutting corners and working overtime: Quality erosion in the service industry. Management Science, 47(7), 894-914.

Pasin, F., \& Giroux, H. (2011). The impact of a simulation game on operations management education. Computers and Education, 57(1), 1240-1254.

Proserpio, L., \& Gioia, D. A. (2007). Teaching the Virtual Generation. Academy of Management Learning \& Education, 6(1), 69-80.

Wilson, L. E., \& Sipe, S. R. (2014). A Comparison of Active Learning and Traditional Pedagogical Styles in a Business Law Classroom. Journal of Legal Studies Education, 31(1), 89-105. 